\title{
Evaluation of a novel simulation method of teaching B-lines: hand ultrasound with a wet foam dressing material
}

\author{
YJ Cho ${ }^{1 *}, \mathrm{KH} \mathrm{Lee}{ }^{2}, J H \mathrm{Ahn}^{2}, \mathrm{CK} \mathrm{Hong}^{2}, \mathrm{YR} \mathrm{Ha}{ }^{2}$ \\ From 10th WINFOCUS World Congress on Ultrasound in Emergency and Critical Care \\ Kuala Lumpur, Malaysia. 16-19 November 2014
}

\section{Background}

Lung ultrasound simulations for pathologic conditions are not readily available for bedside teaching. Recently hand ultrasound was introduced as a new model of simulating lung ultrasound including normal lung sliding, stratosphere sign, and lung point. However no effective method of teaching B-lines has been reported.

\section{Objective}

The aim of this study was to evaluate effectiveness of a novel mode of teaching B-lines made by using hand ultrasound with a wet foam dressing material simulating a wet lung.

\section{Patients and methods}

All subjects enrolled were medical school students who were novice for lung ultrasound. All subjects attended a 20-mintutes lecture about lung ultrasound using simulated video clips of A-lines, B-lines, and lung sliding for $20 \mathrm{~min}$ utes and 20-minutes post-test was given. A post-test were composed of questions on the choice between A-lines and $\mathrm{B}$-lines and the presence of lung sliding using randomly mixed 20 real and 20 simulated video clips using hand ultrasound with or without a wet foam dressing materials. At the end of the post-test, the correct answer was revealed and discussed. Paired $t$ test was used to compare the each score of A-lines, B-lines, and lung sliding between the real images and simulated models.

\section{Results}

There were 56 male and 20 female with mean age of 25.1 \pm 2.8 . The mean of the total score was $51.9 \pm 4.9$ for the real video clips and $52.3 \pm 5.0$ for the simulated models $(\mathrm{P}=0.485)$. The mean of the score for correct answers between A-lines and B-lines was $17.5 \pm 2.6$ for the real video clips and $17.0 \pm 2.0$ for the simulated clips $(\mathrm{P}=0.0961)$ The mean of the score for lung sliding was $16.0 \pm 2.7$ in real image and $17.6 \pm 2.6$ in simulated images $(P<0.001)$.

\section{Conclusion}

The novel B-line teaching model by using a hand ultrasound with a wet foam dressing material was readily available and effective method to simulate pulmonary interstitial syndrome.

\section{Authors' details \\ ${ }^{1}$ Department of Internal Medicine, Seoul National University Bundang Hospital, South Korea. ${ }^{2}$ Department of Emergency Medicine, Bundang Jesaeng Hospital, South Korea.}

Published: 9 March 2015

\section{Reference}

1. Shokoohi H, Boniface K: Hand Ultrasound: A High-fidelity Simulation of Lung Sliding. Acad Emerg Med 2012, 19(9):E1079-83.

doi:10.1186/2036-7902-7-S1-A30

Cite this article as: Cho et al:: Evaluation of a novel simulation method of teaching B-lines: hand ultrasound with a wet foam dressing material. Critical Ultrasound Journal 2015 7(Suppl 1):A30.

\footnotetext{
* Correspondence: youngrock.ha@gmail.com

'Department of Internal Medicine, Seoul National University Bundang

Hospital, South Korea

Full list of author information is available at the end of the article
}

(c) 2015 Cho et al; licensee Springer. This is an Open Access article distributed under the terms of the Creative Commons Attribution License (http://creativecommons.org/licenses/by/4.0), which permits unrestricted use, distribution, and reproduction in any medium, provided the original work is properly cited. 